\title{
French neurologists Charles Foix and Jean Alfred Émile Chavany and French pediatrician Julien Marie and the Foix-Chavany-Marie syndrome
}

\author{
Ali Ç. Turgut ${ }^{1} \cdot$ R. Shane Tubbs ${ }^{2,3} \cdot$ Mehmet Turgut $^{4,5}$ \\ Received: 10 June 2019 / Accepted: 30 June 2019 / Published online: 12 July 2019 \\ (C) Springer-Verlag GmbH Germany, part of Springer Nature 2019
}

\section{Introduction}

The eponym "Foix-Chavany-Marie syndrome" (FCMS), also called bilateral anterior opercular syndrome, identifies three physicians who contributed to defining it [2]. In 1926, the syndrome was detailed by the French neurologists Charles Foix (1882-1927) and Jean Alfred Émile Chavany (18921959) together with French pediatrician Julien Marie (18991987), although it was first described by Magnus in 1837 [2, 3]. A developmental form of FCMS was described by Worster-Drought during the 1950s [4].

Charles Foix was born in Salies-de-Béarn in the PyreneesAtlantiques of France in 1882 [2]. He received his medical education at the University of Paris and was a student of Pierre Marie (1853-1940) at the Hôpital de la Salpêtrière in Paris. He taught in the clinic of the famous French neurologist Georges Charles Guillain (1876-1961) at the Salpêtrière. His original study concerned arterial thrombosis, and he wrote a book on the anatomy of cerebrovascular structures based on his

R. Shane Tubbs

shanet@seattlesciencefoundation.org

Ali Ç. Turgut

alicaglar304.at@gmail.com

Mehmet Turgut

drmturgut@yahoo.com

1 Hacettepe University School of Medicine, Ankara, Turkey

2 Seattle Science Foundation, 550 17th Avenue, Suite 600, Seattle, WA 98122, USA

3 Department of Anatomical Sciences, St. George's University, University Centre Grenada, West Indies, Grenada

4 Department of Neurosurgery, Adnan Menderes University School of Medicine, Aydin, Turkey

5 Department of Histology and Embryology, Adnan Menderes University Health Sciences Institute, Aydin, Turkey autopsy findings. He died on March 22, 1927 [2]. Jean Alfred Émile Chavany was born in Condat, France, in 1892 and died 1959, while Julien Marie was born in France in 1899 and died in 1987 [2].

\section{Foix-Chavany-Marie syndrome}

FCMS is a distinct form of pseudobulbar palsy characterized by acute-onset severe dysarthria and dysphagia due to bilateral anterior opercular cortex lesions (Fig. 1 and Cover) [1, 2]. Interestingly, the condition is associated with "automatic voluntary dissociation" in which the involuntary reflex motor movements of the affected muscles, such as smiling or crying, are preserved, but bilateral facial, lingual, pharyngeal, and masticatory muscles innervated by the lower cranial nerves (CNs) including V, VII, IX, X, and XII are affected.

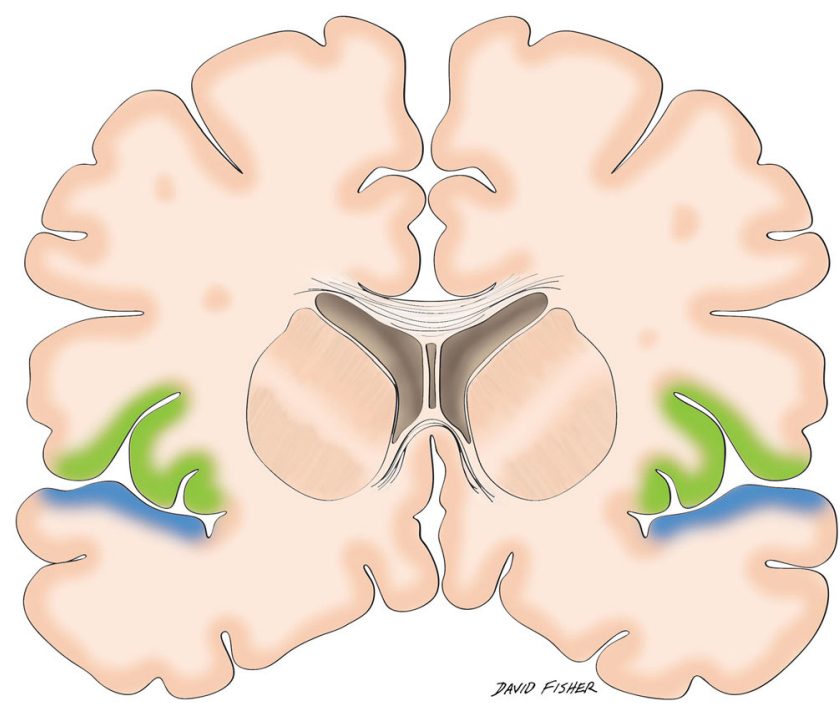

Fig. 1 and Cover Lesions appearing in the highlighted regions are characteristic of Foix-Chavany-Marie syndrome 
Additionally, there is limb weakness as well as bowel and bladder incontinence [1]. Clinically, it can occur at any age in acute, subacute, or chronic forms, with an incidence lower than $1 / 1,000,000$ [1]. FCMS is caused by congenital or acquired bilateral lesions of the anterior opercula attributable to ischemic vascular lesions, infections, or neurodegenerative disorders of the central nervous system, neoplasms, hydrocephalus, or epilepsy [1]. Since the advent of CT and MRI, this syndrome has been increasingly reported in the literature and there are less than 150 reported cases. It should be distinguished from bulbar paralysis and disorders involving the $\mathrm{CNs}$ and from neuromuscular junction dysfunctions such as myasthenia gravis and botulism. Management requires a multidisciplinary therapeutic approach and the prognosis is usually related to the underlying etiology.

\section{References}

1. Bruyn GW, Gathier JC (1969) The operculum syndrome. In: Vinken PJ, Bruyn GW (eds) Handbook of clinical neurology, vol 2. Elsevier Science BV, Amsterdam, pp 776-783

2. Foix C, Chavany JA, Marie J (1926) Diplegie facio-linguomasticatrice d'origine souscorticale sans paralysie des members. Rev Neurol 33:214-219

3. Magnus A (1837) Fall von Aufhebund dis willenseinflusses auf einige Hirnnerven. Arch Anat Physiol Wiss Med:258-266

4. Worster-Drought C (1953) Demonstration of neurological cases held at the West End Hospital for nervous diseases. Postgrad Med J 29: 316-321

Publisher's note Springer Nature remains neutral with regard to jurisdictional claims in published maps and institutional affiliations. 